\title{
Arduino-based Mini Shaker for Automatic Chemical Solution Mixer
}

\author{
Nur Hudha Wijaya ${ }^{1}$, Dian Friska Novela ${ }^{2}$, Nishith Shahu ${ }^{3}$, Mian Usman Sattar ${ }^{4}$ \\ ${ }^{1,2}$ Department of Electrical Engineering, Universitas Muhammadiyah Yogyakarta, Yogyakarta, Indonesia \\ ${ }^{3}$ Departement of Electrical Engineering, Gujarat Technological University, India \\ ${ }^{4}$ Information Systems, University of Management and Technology, Pakistan. \\ hudhapmy@gmail.com,dian.friskanovela.2015@vokasi.umy.ac.id,nish2687@gmail.com,usman.sattar@umt.edu.pk
}

\begin{abstract}
The purpose of the research was to make an Arduino-based mini shaker for automatic mixing of chemical solutions. The use of the tool was expected to save time and energy in the process of mixing chemical solutions, facilitate laboratory workers in mixing the chemical solutions quickly and efficiently, and for a safety reason in the laboratory. The design of this tool consists of a time sensor, speed sensor, microcontroller, motor driver and Dc motor. This tool can regulate the speed of a DC motor with three speeds namely 100 RPM low, 150 normal RPM, and 180 high RPM. Based on the results of motor speed measurements, the average error at the motor speed is low $1.4 \%$, normal $2.5 \%$, and high $2.54 \%$, and the average error at the timer is 1 minute $0.03 \%, 2$ minutes $0,1 \%, 3$ minutes $0.05 \%$, 4 minutes $0.016 \%$, and 5 minutes $0.03 \%$.
\end{abstract}

Keywords - chemical solution, mixer, Arduino

\section{INTRODUCTION}

In researching in a laboratory, it is often found that work is carried out repeatedly in a certain period. Some examples of work are mixing chemical solutions in the Tissue Culture Laboratory, Biology Laboratory, and Pharmacy.

Mixing is a process of making a solution to produce a distribution of two or more ingredients to be homogeneous. If mixing the solution is done manually, it will be less time and energy-efficient. Besides, there are several solutions which are dangerous to touch.

The stirring motion direction of the device, in general, is horizontal so that the homogeneity of a mixture is difficult to achieve. A mini shaker for an automatic chemical solution mixer is necessary, expected to increase the safety of laboratory users, save time and energy in the process of mixing chemical solutions, minimize the occurrence of contamination in the solution to be mixed due to the presence of material entering the solution, and contribute both in the world of health and of science and technology today.

This shaker is driven by a DC motor with speed regulated using a microcontroller. Some previous researchers have conducted research on controlling DC motors using a microcontroler. Khan conducted research on DC motor speed control by an embedded PI controller with a hardware-in-loop simulation. Conventional controllers such as PD, PI and PID have been widely used in industry and have shown good control performance for different industrial plants [1]. Jia Yunfei designed the wireless control of DC motors based on the MCU MSP430. A motor wireless controller that can control the speed and turn of a DC motor using ASK modulation, coding and decoding methods has been designed
[2]. Rajeshkanna conducts research into the modern speed control of an excited DC Motor separately with the Boost converter field amplifier control method.

An innovative technique of speed control of DC motors that are excited separately by a field control converter Boost is being discussed [3]. The design and development of digital PID controllers for DC motor drive systems using embedded platforms for cellular robots was investigated by Gohiya. Cellular Robot Systems for monitoring these parameters using wireless networks have been considered here and were developed based on the ARM-Linux platform [4]. The design and performance analysis of a two-axis automatic solar tracking system for a steam generator was investigated by Paul. DC motors are used to develop and implement prototypes of automatic two-axis solar tracking systems and cost-effective systems for water heating applications [5].

Speed control for DC motors with pulse width modulation (PWM) method using an infrared remote control based on the ATmega16 microcontroller was investigated by Agung. Direct current (DC) motor speed control for various applications is very important [6]. The new framework based on the AVR microcontroller for automatic DC motor testing and analysis was investigated by Kaur. The embedded platform has been developed using an AVR microcontrollerbased hardware interface, data acquisition card, control module, and graphical programming environment [7].

The development of a powerful microcontroller-based output feedback control for assisted limbs was investigated by Ashmi. The drive circuit design is based on data obtained from video analysis of human movers and the PIC18F is a Master controller which helps in moving the DC series motor so that it mimics the human gait cycle [8]. Kanth conducted research on designing motor speed control using LabVIEW to control air flow in a wind tunnel. Wind tunnels are used in aerodynamics and heat transfer research to analyze various effects on solid objects when air is forced [9]. Araari conducts research on embedded Linux-based DC motor control. Pulse Width Modulation is used to move the motor at the desired speed [10].

Previous researchers have examined DC motors to regulate their speed. Sai controls the speed of the DC motor using voice commands. Using sound as an input control will reduce manual operation [11]. Control of Real Time Speed of DC Motors by Temperature Variations Using LabVIEW and Arduino was investigated by Asha. Because the motor speed is controlled by temperature variations, the temperature 
measurement circuit is connected via LabVIEW [12]. The design and implementation of adaptive PID controllers for speed control of DC motors was investigated by Sahputro. Design and implementation of adaptive PID control strategies for controlling the angular speed of DC motors [13]. The development of fuzzy logic controller for DC motors using personal computers and inexpensive microcontrollers was investigated by Thanh. Development of various types of electric motors, traditional DC motors are still widely used in robot and industrial applications because these types of electric motors have high quality control [14]. The speed position control system for DC motors was investigated by Ciucur. This system is controlled by a microprocessor, or microcomputer, which determines the optimal speed profile for each movement and trajectory [15].

The new framework based on the AVR microcontroller for automatic DC motor testing and analysis was investigated by Kaur. A single user-friendly platform that can be used to automate the dc motor testing process provided for various analyzes such as determining the characteristics of speedtorque, calculating losses, and estimating efficiency and can also function as a dc motor speed controller [7]. Analysis of solar-based closed loop DC-DC converters using PID and fuzzy logic control for separate excited motor drives was investigated by Jayaprakash. An analysis of solar-based closed loop DC-DC converters using PID and Fuzzy Logic Control for separate motor drives [16]. Arici conducted research on the self-tuning speed control of permanent magnet DC motors. The problem of speed control of permanent magnet DC motors is considered in the presence of unknown interference and factory parameters [17].

Control of DC electric drive with a fuzzy system was investigated by Bara. The solution to the problem of principle DC power drives is powered by static converters, at low speeds and load torque [18]. Angalaeswari controls the speed of a permanent magnet DC motor (PM) using Arduino and LabVIEW. Control the speed of a DC Permanent Magnet Motor (PMDC) using the VIEW Lab which is connected to Arduino. That [19]. Jaziri controls a DC Motor with a Closed Loop using a low-cost single-board microcontroller based on embedded Linux. The possibility to use a cheap computer credit card sized like a Beaglebone board for the realization of real-time motor control - that is, the control of a DC motor speed based on the PI-controller [20].

From some previous researchers, this paper is different from previous research papers. This paper presents the speed control of a dc motor used for stirring chemical solutions. The controls used in this paper use Arduino. This system is equipped with a sensor to read DC motor speed and there is an LCD display.

\section{METHODS}

The control speed of a dc motor for stirring chemical solutions is shown in Figure 1. From the picture it appears that the system consists of input from a speed sensor, an Arduino type microcontroller and a motor driver [21] - [25].

When the user pressed the ON/OFF button, the electricity flowed into the circuit. Setting the timer and motor speed was done before starting the process. The motor speed would be regulated by a driver circuit with three speeds (low 100 RPM, normal 150 RPM, and high 180 RPM), and all circuits were controlled by a microcontroller system [26]-[30].

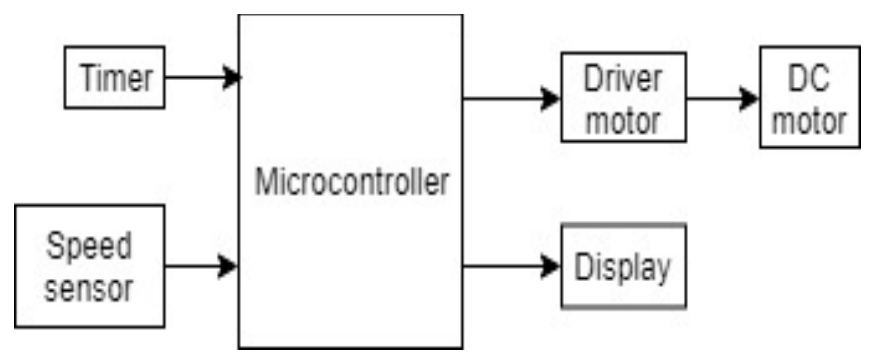

Fig. 1. System block diagram

Pressing the enter button would actuate the motor driver activated by the microcontroller IC, and then the motor and timer would work to start the mixing process. The sensors read the speed generated by the DC motor displayed on the LCD. The system block diagram is illustrated in figure 1 .

\section{A. System work flow}

The system work flow is shown in the Figure 2. When the ON/OFF button was pressed, the LCD initialization started. There is a timer with a selection of $1,2,3,4$, or 5 minutes for mixing the chemical solution and setting the motor speed with a selection of 100,150 , and 180 RPMs.

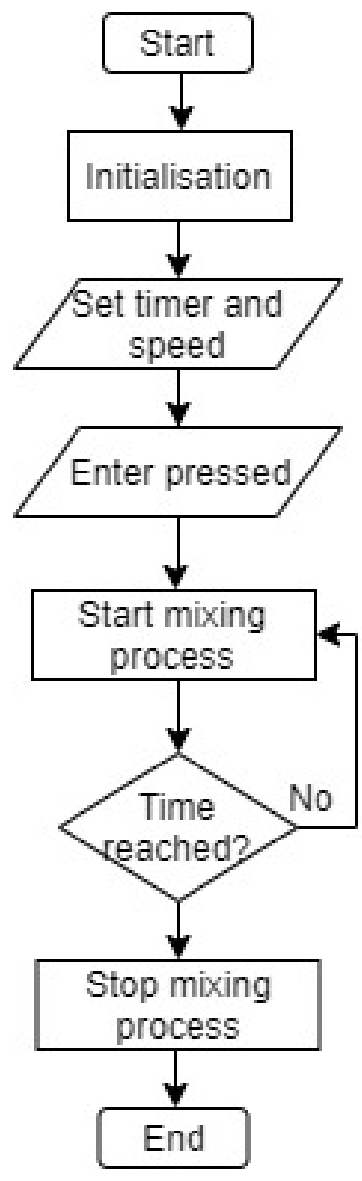

Fig. 2. System work flow diagram

Pressing the enter button would activate the timer so that the motor would work and do the mixing process according to the time. When the time had been up, the motor and timer would be OFF. If the mixing process would need to continue, 
the enter button needed to be pressed, otherwise, the END button.

\section{B. Data analyze}

In this study, data analysis was calculated from three parameters, namely the average, the deviation, and the error. The average was the result of the division of the number of data taken or measured by the number of data retrieval or measurements. The deviation was the average value difference between the desired and the measured values, while the error was the difference among the mean of each data.

\section{IMPLEMENTATION}

The standard operating procedures for device utilization are as follows. Preparing a sample that will be mixed. Ensuring that the test tube containing the sample has been installed in the mini shaker device module. Connecting the device to the power supply. Pressing the ON/OFF button to turn on the appliance. Initialing the LCD. Setting the timer to set the time of stirring the chemical solution by pressing the mode button and Up/Down for timer selection. Setting the motor speed with low, normal, or high speed by pressing the mode button and Up/Down for RPM selection. Press the enter to start the stirring process. Pressing the ON/OFF button to turn off the appliance after the mixing process finished, and the motor and timer stopped. The hardware is shown in Figure 3 .

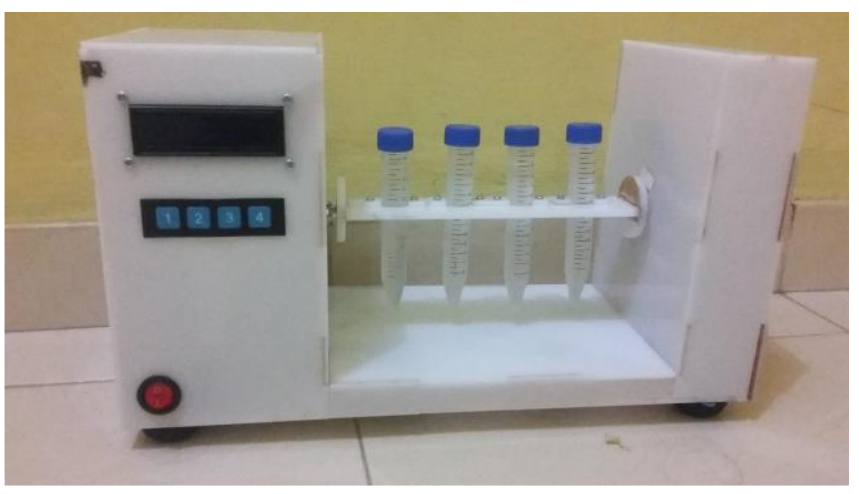

Fig. 3. Hardware visualization

\section{A. Firmware design}

The module used the Arduino application to make the program. The program used was a program to adjust motor speed and timer selection on the device.

\section{B. System test}

The first step taken for module testing was preparing a comparison device (stopwatch and digital tachometer) and a mini shaker device module, connecting the mini shaker device module with the power supply, pressing the ON/OFF button to turn on the device, pressing the mode button for timer selection (1, 2, 3, 4, and 5 minutes) and the motor speed (100, 150 , and 180 RPMs) to be measured. Finally, pressing the start button together with the stopwatch, pointing the tachometer towards the media to be measured, making sure the stopwatch and timer on the module stop simultaneously and recording the results on the worksheet.

\section{RPM measurement test}

The above measurements were made on August 11, 2017, at 3:40 pm West Indonesia Time, the data collection at the motor speed of 100 RPM was tested 20 times with the highest difference being 10 in table 14 and the lowest difference being 1 in tables 1, 3, 9, and 19. For the average results obtained in the final assignment, the module is 101.55 , with a deviation of 1.45 and Error $1.4 \%$.

The data collection at 150 RPM motor speed was tested 20 times, with the highest difference of 15 in tables 10 and 12 and the lowest difference of 3 in tables 9, 11, 13, 16, 17, and 20. The average obtained in the final project module was 146.25 , with a deviation of 3.75 and an error of $2.5 \%$.

Based on the data retrieval that has been done, Table 1 presents the data obtained from the measurement results.

TABLE I. RPM MEASUREMENT TEST RESULT

\begin{tabular}{|c|c|c|c|}
\hline \multirow{2}{*}{$\boldsymbol{R} P M$} & \multicolumn{3}{|c|}{ Data analyze } \\
\cline { 2 - 4 } & Average & Deviation & Error \\
\hline Low (100 RPM) & 101.55 & 1.45 & $1.4 \%$ \\
\hline Normal (150 RPM) & 146.25 & 3.75 & $2.5 \%$ \\
\hline High (180 RPM) & 178.05 & 4.65 & $2.54 \%$ \\
\hline
\end{tabular}

Table 1 describes the measurement data based on the results of the averages, deviations, and errors. It obtained two factors affecting the results, namely the DC motor and sensor module. The sample weight affected the results obtained so that the rotation speed of the motor was up and down, socalled not stable. The speed of the response time and the stable time of the sensor module also affected the results obtained either different or the same as the comparison device.

\section{Timer measurement test}

Table 2 describes the measurement data based on the results of the averages, deviations, and errors. When the data collection process had been done manually, namely, when the process of starting (pressing) and stopping the stopwatch was not done simultaneously with the final assignment module, the data obtained at the comparison (stopwatch) would not be according to the device designed.

TABLE II. TIMER MEASUREMENT TEST RESULT

\begin{tabular}{|c|c|c|c|}
\hline \multirow{2}{*}{$\begin{array}{c}\text { Time } \\
\text { (minute) }\end{array}$} & Dverage & Deviation & Error \\
\cline { 2 - 4 } & 59.98 & 0.02 & $0.03 \%$ \\
\hline 1 & 119.88 & 0.12 & $0.1 \%$ \\
\hline 2 & 180.09 & 0.09 & $0.05 \%$ \\
\hline 3 & 240.04 & 0.04 & 0.016 \\
\hline 4 & 300.11 & 0.11 & $0.03 \%$ \\
\hline 5 & & & \\
\hline
\end{tabular}

\section{CONCLUSION}

Based on the results of motor speed measurements, the average error at motor speed is at low $1.4 \%$, normal $2.5 \%$, and high $2.54 \%$, and the average error on the timer is 1 minute $0.03 \%, 2$ minutes $0.1 \%, 3$ minutes $0.05 \%, 4$ minutes $0.016 \%$, and 5 minutes $0.03 \%$. Based on the results of planning and making the module the Arduino-based automatic chemical solution mixer, it is concluded that this device is suitable for use because the error rate is still below the error tolerance of $5 \%$. 


\section{REFERENCES}

[1] H. S. Khan and M. B. Kadri, "DC motor speed control by embedded PI controller with hardware-in-loop simulation," in 2013 3rd IEEE International Conference on Computer, Control and Communication (IC4), 2013, pp. 1-4.

[2] Jia Yunfei, Liu Jiping, and Jiang Feng, "Design of DC motor wireless controller based on MCU MSP430," in Proceedings 2013 International Conference on Mechatronic Sciences, Electric Engineering and Computer (MEC), 2013, pp. 3492-3495.

[3] G. Rajeshkanna, "Modern speed control of separately excited DC Motor by Boost converter fed field control method," in 2013 International Conference on Computer Communication and Informatics, 2013, pp. 1-7.

[4] C. S. Gohiya, S. S. Sadistap, S. A. Akbar, and B. A. Botre, "Design and development of digital PID controller for DC motor drive system using embedded platform for mobile robot," in 2013 3rd IEEE International Advance Computing Conference (IACC), 2013, pp. 52-55.

[5] M. A. J. Paul, "Design and performance analysis of automated two axis solar tracking system for steam generation," in 2013 International Conference on Energy Efficient Technologies for Sustainability, 2013, pp. 432-437.

[6] I. G. A. P. R. Agung, S. Huda, and I. W. A. Wijaya, "Speed control for DC motor with pulse width modulation (PWM) method using infrared remote control based on ATmega16 microcontroller," in 2014 International Conference on Smart Green Technology in Electrical and Information Systems (ICSGTEIS), 2014, no. November, pp. 108-112.

[7] P. Kaur and S. Chatterji, "A novel framework based on AVR microcontroller for automated testing and analysis of DC motors," in 2014 Recent Advances in Engineering and Computational Sciences (RAECS), 2014, pp. 1-6.

[8] M. Ashmi, S. Jayaraj, and K. S. Sivanandan, "Development of a robust microcontroller based output feedback control for assistive limb," in 2014 IEEE Conference on Biomedical Engineering and Sciences (IECBES), 2014, no. December 2014, pp. 193-197.

[9] B. B. V. Kanth, G. S. Pavankumar, S. Arunkumar, and M. Venkatesan, "Design of motor speed control using LabVIEW for air-flow control in wind tunnels," in 2014 IEEE International Conference on Computational Intelligence and Computing Research, 2014, pp. 1-4.

[10] T. Araari, I. Jaziri, L. Charaabi, and K. Jelassi, "DC motor control based on embedded Linux," in 2014 International Conference on Electrical Sciences and Technologies in Maghreb (CISTEM), 2014, pp. $1-6$.

[11] T. M. Sai and S. K. Kumar, "Speed control of DC motor using voice commands," in 2016 International Conference on Computation of Power, Energy Information and Commuincation (ICCPEIC), 2016, pp. 800-803.

[12] K. R. Asha, P. S. Tasleem, A. V. Ravi Kumar, S. M. Swamy, and K. R. Rekha, "Real Time Speed Control of a DC Motor by Temperature Variation Using LabVIEW and Arduino," in 2017 International Conference on Recent Advances in Electronics and Communication Technology (ICRAECT), 2017, pp. 72-75.

[13] S. D. Sahputro, F. Fadilah, N. A. Wicaksono, and F. Yusivar, "Design and implementation of adaptive PID controller for speed control of DC motor," in 2017 15th International Conference on Quality in Research (QiR): International Symposium on Electrical and Computer Engineering, 2017, vol. 2017-Decem, no. 1, pp. 179-183.

[14] S. N. Thanh, K. N. Thanh, C. N. The, P. P. Hung, and H. H. Xuan, "Development of fuzzy logic controller for DC motor using personal computer and inexpensive microcontroller," in 2014 13th International Conference on Control Automation Robotics \& Vision (ICARCV), 2014, vol. 2014, no. December, pp. 1310-1314.

[15] V.-V. Ciucur, "Speed position control system for DC motor," in 2014 16th International Conference on Harmonics and Quality of Power (ICHQP), 2014, pp. 876-879.
[16] S. Jayaprakash and V. Ramakrishnan, "Analysis of solar based closed loop DC-DC converter using PID and fuzzy logic control for separately excited motor drive," in 2014 IEEE National Conference on Emerging Trends In New \& Renewable Energy Sources And Energy Management (NCET NRES EM), 2014, pp. 118-122.

[17] M. Arici and A. O. Arslan, "Self-tuning speed control of permanent magnet DC motor," in 2015 9th International Conference on Electrical and Electronics Engineering (ELECO), 2015, no. 4, pp. 1113-1116.

[18] A. Bara, S. Dale, C. Rusu, and H. Silaghi, "DC electrical drive control with fuzzy systems," in 2015 13th International Conference on Engineering of Modern Electric Systems (EMES), 2015, vol. 1, no. 1, pp. $1-4$.

[19] S. Angalaeswari, A. Kumar, D. Kumar, and S. Bhadoriya, "Speed control of permanent magnet (PM)DC motor using Arduino and LabVIEW," in 2016 IEEE International Conference on Computational Intelligence and Computing Research (ICCIC), 2016, pp. 1-6.

[20] I. Jaziri, L. Charaabi, and K. Jelassi, “A closed Loop DC Motor Control using low cost single-board microcontroller based on embedded Linux," in 2016 International Conference on Electrical Sciences and Technologies in Maghreb (CISTEM), 2016, pp. 1-5.

[21] U. Sarma and P. . Bordoloi, "Speed Control of A DC Motor Using PLC and PIC Microcontroller," in 2017 14th IEEE India Council International Conference (INDICON), 2017, pp. 1-6.

[22] N. M. A. Mohamed, A. A. A. Abdalaziz, A. A. A. Ahmed, and A. A. A. Ahmed, "Implementation of a PID control system on microcontroller (DC motor case study)," in 2017 International Conference on Communication, Control, Computing and Electronics Engineering (ICCCCEE), 2017, no. 1, pp. 1-5.

[23] M. Rad, F. Simonca, A. Fratean, and P. Dobra, "Embedded speed control of BLDC motors using LPC1549 microcontroller," in 2016 IEEE International Conference on Automation, Quality and Testing, Robotics (AQTR), 2016, pp. 1-5.

[24] F. E. V. Taveiros, L. S. Barros, and C. M. V. Barros, "Conventional and adaptive strategies applied to DC motor control using microcontroller PIC18F4520," in 2018 Simposio Brasileiro de Sistemas Eletricos (SBSE), 2018, no. 4, pp. 1-6.

[25] P. Surana, Sreejith R., and K. R. Rajagopal, "A low cost position sensorless brushless DC motor drive," in 2016 IEEE International Conference on Power Electronics, Drives and Energy Systems (PEDES), 2016, vol. 2016-Janua, pp. 1-5.

[26] C. D. Britto and P. Kumar, "Analysis of Boost converter fed DC motor," in 2016 International Conference on Computation of Power, Energy Information and Commuincation (ICCPEIC), 2016, pp. 487489.

[27] L. Lindner et al., "Issues of exact laser ray positioning using DC motors for vision-based target detection," in 2016 IEEE 25th International Symposium on Industrial Electronics (ISIE), 2016, vol. 2016-Novem, pp. 929-934.

[28] S. Bilgaiyan, S. James, S. S. Bhonsle, S. Shahdeo, and Keshavamurthy, "Android based signboard detection using image and voice alert system," in 2016 IEEE International Conference on Recent Trends in Electronics, Information \& Communication Technology (RTEICT), 2016, pp. 1488-1491.

[29] A. Kumar, H. Saraf, and R. Kumar, "Hardware design of closed loop four quadrant dc motor drive with regenerative braking," in 2018 2nd International Conference on Inventive Systems and Control (ICISC), 2018, pp. 287-292.

[30] C.-T. Chu, Y.-K. Wang, and H.-L. Liang, "SISO PID-fuzzy controller for BLDC motor speed control base on low cost MSP430 solution," in 2016 5th International Symposium on Next-Generation Electronics (ISNE), 2016, pp. 1-2. 